\title{
Fontes de conhecimento/tecnologia para o agronegócio da soja em Mato Grosso
}

\author{
Adelice Minetto Sznitowski \\ Universidade do Estado de Mato Grosso - UNEMAT \\ adeliceadm@gmail.com \\ Adelice MinettoDoutora em AdministraçãoMestre em Engenharia de ProduçãoProfessora \\ efetiva na Universidade do Estado de Mato Grosso-UNEMAT
}

\begin{abstract}
RESUMO
O propósito deste estudo é apresentar as fontes de conhecimento/tecnologia no âmbito do agronegócio da soja no Mato Grosso. O desempenho do agronegócio brasileiro, em especial da soja mato-grossense é atribuído à ampla rede de agentes que ao longo da cadeia se constituem como fontes de inovação, com destaque para indústria de insumos e instituições públicas e privadas que desenvolvem pesquisas e difundem tecnologias. Nesse sentido, a investigação teve como foco os fornecedores de conhecimento/tecnologia para o processo produtivo do grão tais como as revendas de insumos, as fontes de conhecimento especializado como o Sistema Nacional de Pesquisa Agropecuária (SNPA) dentre outros. Assim, a contribuição do trabalho é apresentar as fontes de inovação e sua dinâmica de forma contextualizada.
\end{abstract}

Palavras-chave: Agronegócio da Soja. Fontes de Conhecimento/tecnologia. Transferência.

\begin{abstract}
The purpose of this study is to present the sources of knowledge / technology in the field of soybean agribusiness in Mato Grosso. The performance of Brazilian agribusiness, especially Mato Grosso soybean is attributed to the wide network of agents that along the chain constitute as sources of innovation, with emphasis on the industry of inputs and public and private institutions that develop research and diffuse technologies. In this sense, the research focused on knowledge / technology suppliers for the grain production process, such as resale of inputs, specialized knowledge sources such as the National Agricultural Research System (SNPA), among others. Thus, the contribution of the work is to present the sources of innovation and its dynamics in a contextualized way.
\end{abstract}

Keywords: Soybean Agribusiness. Sources of Knowledge/technology. Transfer.

\section{INTRODUÇÃO}

A agricultura é tratada atualmente como um complexo de bens e serviços e envolve uma diversidade de agentes e relações ao longo de sua cadeia. Nesse sentido, Batalha (2002), convergindo com a conceituação inicial cunhada por Davis e Goldberg (1957), define o termo agribusiness ou agronegócio como o conjunto de negócios relacionados à agricultura dentro do ponto de vista econômico. O agronegócio é o "conjunto de todas as operações que abrange desde o setor produtor de insumos para a atividade produtiva primária, até a distribuição do alimento, produção de energia e fibras" (ZYLBERSZTAJN; SCARE, 2003, p. 15). Trata-se de um setor amplo, pois engloba a soma de quatro segmentos: (a) insumos para a 
agropecuária, (b) produção agropecuária básica ou, como também é chamada, primária ou "dentro da porteira", (c) agroindústria (processamento) e (d) distribuição, como cita o Centro de Estudos Avançados em Economia Aplicada (CEPEA, 2014).

O agronegócio no Brasil dispõe de condições propícias para a produção e, além disso, é representativo para a economia brasileira. As condições que favorecem a produção são disponibilidade de terras somada às tecnologias para correção de solos, materiais genéticos adaptados e suporte tecnológico em máquinas, equipamentos e demais insumos que permitiram aumentar a produção em áreas consideradas de baixo potencial produtivo. O apoio de uma rede de tecnologias tropicais lideradas pela Empresa Brasileira de Pesquisa Agropecuária (EMBRAPA) tem tornado o Brasil destaque em produtividade (ROSCOE, 2013; PARENTE, 2011; CAPETTI, 2013; CONTINI, 2014). Quanto à representatividade, decorrente de fatores favoráveis à produção, o setor agrícola desempenha importante papel. A agricultura foi determinante para que o Brasil alcançasse uma média de 3,5\% de crescimento no PIB real entre 2005 e 2013 (OCDE-FAO, 2015).

Esse desempenho econômico deriva do forte crescimento nas últimas três décadas que fez a produção agrícola mais do que dobrar de volume em comparação ao nível registrado em 1990. As exportações da agricultura e das indústrias agroalimentares somaram mais de US\$ 86 bilhões em 2013, sendo responsáveis por 36\% do total das exportações. O setor contribui fortemente para a balança comercial do País, fazendo com que essas exportações compensaram os déficits de outros setores, evidenciando o papel do agronegócio como um arrecadador de moeda estrangeira (OCDE-FAO, 2015).

Os resultados visíveis na competitividade e no dinamismo desse setor derivam das inovações introduzidas na agricultura ao longo do tempo. O Brasil é considerado um exemplo de excelência na produção de conhecimento aplicado à produção agropecuária. Para Vieira Filho e Silveira (2012) e Vieira Filho e Pinto Vieira (2013), a agricultura não é um setor marginal da economia, ela incorpora de forma contínua novas tecnologias. As inovações resultantes fizeram a produção brasileira aumentar significativamente sem haver proporcionalmente o aumento das áreas cultivadas. Dados do Ministério da Agricultura, Pecuária e Abastecimento (MAPA, 2010) mostram que o cultivo de grãos no período de 1960 a 2010, derivados dos avanços tecnológicos, aumentou em mais de $774 \%$ a produção e a área plantada em pouco mais de $100 \%$. Caso o País mantivesse a mesma tecnologia de 1960, ocuparia mais 145 milhões de hectares de terra, ao invés de 47,5 milhões em 2010.

Esse dinamismo da agricultura no Brasil foi baseado na disponibilidade de novas tecnologias adaptadas à agricultura tropical, a adoção de métodos modernos de gestão, 
instrumentos financeiros dentre outros (OECD-FAO, 2015). A inovação na produção agrícola foi fundamental para o aumento da eficiência no campo. Isso é atribuído ao agricultor, às empresas, à pesquisa e toda a cadeia (CONTINI, 2014).

Nesse contexto, o agronegócio da soja merece destaque por ser uma das principais commodities produzidas no mundo e por isso faz parte do conjunto de atividades agrícolas com maior destaque no mercado mundial (IMEA, 2015; HIRAKURI; LAZZAROTTO, 2014; BARROS; MENEGATTI, 2014; RIBEIRO, 2014). É o quarto grão mais consumido e produzido globalmente, bem como a principal oleaginosa cultivada planeta (HIRAKURI; LAZZAROTTO, 2014).

O destaque da soja no mercado mundial decorre dos diferentes usos em diversos segmentos. Atende diferentes demandas, dentre as quais da indústria alimentícia, automobilística (matéria prima para biocombustíveis), indústria cosmética (RIBEIRO, 2014). Tem seu cultivo concentrado em três países: Estados Unidos, Brasil e Argentina que somam $82 \%$ da produção mundial (HIRAKURI; LAZZAROTTO, 2014). No Brasil, as principais regiões produtoras de soja são a Sul e Centro-Oeste que agrupam atualmente (safra 2014/2015) 81,04\% da área nacional (OECD-FAO, 2015). Embora sejam as maiores regiões produtoras do grão, a soja começa a avançar também nas direções Norte e Nordeste, para estados como Maranhão Tocantins, Piauí e Bahia - conhecida como MATOPIBA (HIRAKURI; LAZZAROTTO, 2014).

Na região Centro Oeste, o Mato Grosso nos últimos vinte anos se tornou uma das maiores fronteiras agrícolas em expansão no Brasil (PALUDO; TIRIONI, 2011). Lidera a produção nacional de soja há 15 safras, com perspectiva de consolidar-se nessa posição. A região que se destaca na produção de soja no estado é a médio-norte, onde se situam os principais municípios produtores: Sorriso (maior município produtor brasileiro), Sinop, Lucas do Rio Verde, Nova Mutum, de acordo com o IMEA (2015).

A importância da produção de soja para o Mato Grosso, contribuiu não somente na produção de alimentos, mas também na inclusão social por propiciar acesso das pessoas a escolas, hospitais, emprego e renda em função desse novo cenário (SOARES NETO, 2014). Isso melhora qualidade vida da população, pois em 2015 das dez cidades mato-grossenses com maior Índice de Desenvolvimento Humano (IDH), nove tinham na sojicultura sua base econômica, dados estes citados pela Associação dos Produtores de Soja e Milho do Estado de Mato Grosso (APROSOJA - MT, 2016).

Os números sobre a área, produção e produtividade da soja no contexto matogrossense em período mais recente - as últimas dez safras, de 2004/05 a 2014/15 - revelam 
crescimento. Em área aumentou 44\% (de 6.190 para 8.917 milhões de hectares); em produção foi $68 \%$ (de 16.704 para 28.133 milhões de toneladas), o que, segundo dados da Companhia Nacional de Abastecimento (CONAB, 2015) mostra crescimento em produtividade.

Tendo em vista a representatividade do agronegócio brasileiro, a qual deriva do uso de intensivo de tecnologias e a soja produto que se destaca, somado ao fato do Mato Grosso ser o maior produtor brasileiro do grão, teve-se como objetivo central neste estudo explorar as fontes de conhecimento/tecnologia, as quais podem contribuir para processos inovadores no escopo do agronegócio da soja no Estado. Como fontes de conhecimento/tecnologia, foram considerados os fornecedores de "entradas", as quais compreendem tecnologias necessárias ao processo produtivo. Fazem parte desse grupo fornecedores de sementes, fertilizantes, defensivos e máquinas, tecnologias/conhecimento especializados gerados pelo Sistema Nacional de Pesquisa Agropecuária (SNPA), recursos humanos e financeiros e ainda as consultorias agronômicas. Esses agentes tem relação com os sojicultores, e por tal motivo foram objeto de análise nessa pesquisa.

Na sequencia desse trabalho, após a introdução, aborda-se inovação na agricultura e suas fontes, as quais nortearam a elaboração do estudo. Em seguida é exposta a metodologia utilizada que envolveu pesquisa com as fontes de conhecimento/tecnologia para ao agronegócio da soja no contexto mato-grossense. Logo após é apresentada a análise e discussão dos dados envolvendo os tipos de conhecimento/tecnologia fornecidas aos sojicultores e sua transferência, e por fim, apresentam-se as considerações finais e referências que fundamentaram o estudo.

\section{Inovação na Agricultura e sua Dinâmica}

O Brasil dispõe de um quadro institucional com capacidade de produzir conhecimento público necessário para a promoção do crescimento agrícola (VEIRA FILHO 2012; VIEIRA FILHO; CAMPOS; FEREIRA, 2005). A pesquisa agrícola na área da produção é conduzida por instituições públicas, enquanto que na fabricação de insumos é realizada quase que exclusivamente pelo setor privado.

As novas tecnologias para agricultura tropical, resultantes do sistema brasileiro de pesquisa e inovação agrícola, trouxeram inovações na produção e gestão (OCDE-FAO, 2015). A tecnologia e a pesquisa contribuem para o aumento do potencial agrícola brasileiro e a isso podem ser acrescentados mais de 80 milhões de hectares que gradativamente podem ser incorporadas, sem que as reservas legais sejam afetadas (SOARES NETO, 2014) 
Existem no Brasil, como também em outros países, uma rede institucional (pública e privada) que favorece a pesquisa e desenvolvimento agrícola e a transferência de tecnologia para atender demandas científicas e tecnológicas do setor (MUTEIA, 2011; SANTOS, 2012).

O MAPA é responsável pela coordenação da pesquisa agrícola em nível federal por meio da EMBRAPA, já o Ministério do Desenvolvimento Agrário (MDA) lidera a assistência técnica rural e os serviços de extensão focados na agricultura familiar. Em nível nacional, as prioridades para P\&D são estabelecidas pelo governo federal por meio dos ministérios envolvidos em inovação, liderados pelo Ministério da Ciência, Tecnologia e Inovação (MCTI) que também tem importante papel forte na provisão de recursos para pesquisa agrícola, especialmente em nível de P\&D de universidade (OCDE-FAO, 2015).

Como se pode observar, a ciência e a tecnologia desempenham um papel importante no desenvolvimento do setor agrícola brasileiro. Os investimentos em P\&D permitiram avanços científicos na agricultura tropical. Nesse quesito a EMBRAPA desenvolveu variedades adaptadas às baixas latitudes e temperaturas mais elevadas dos ambientes tropicais, controle de pragas, doenças e sistemas de produção. As universidades também contribuíram com pesquisa em áreas complementares às atividades da EMBRAPA, abordando nutrição, saúde e meio ambiente (OCDE-FAO, 2015).

A EMBRAPA é uma instituição pública de referência na geração de inovações para agricultura, foi criada em 1973 e integra o SNPA. A criação da EMBRAPA e do SNPA se tornou um marco no processo que modernizou a agricultura brasileira. Foram instituídos centros de pesquisa por produtos de importância econômica em ambientes quase desconhecidos. A ciência aplicada transformou os solos do Cerrado, antes tidos como impróprios para agricultura em áreas produtivas. Assim foram incorporados milhões de hectares à agricultura brasileira, tornando a região do Cerrado responsável por mais de $1 / 3$ da produção nacional de grãos. Esses resultados fizeram o Brasil se tornar exemplo para o mundo de como transformar recursos naturais não aproveitados em recursos produtivos (CONTINI et al., 2010). Também Barros (2014) reconhece os resultados alcançados como derivados do desenvolvimento de um importante sistema de pesquisa, composto pela EMBRAPA, instituições estaduais, universidades e, mais recentemente, por instituições privadas, destacando ainda a interação entre as instituições públicas e o setor produtivo.

Fazem parte do SNPA, além da EMBRAPA e suas unidades, as Organizações Estaduais de Pesquisa (OEPAs) e ainda outras organizações, públicas e privadas, direta ou indiretamente ligada à atividade de pesquisa agrícola, como as cooperativas, sindicatos, fundações e associações. O objetivo do SNPA é alinhar as diretrizes e estratégias da pesquisa 
agrícola com as políticas de desenvolvimento. Dentro deste sistema, há o planejamento da pesquisa nacional, que apoia a parceria entre diversas instituições no desenvolvimento da ciência e tecnologia. Este esforço tem como objetivo reunir as demandas de pesquisa regional, a fim de melhor apoiar o desenvolvimento agrícola. Na figura 3, mais ao final do trabalho, pode ser observada a representação do SNPA e sua configuração para o contexto matogrossense.

\subsection{Inovações na agricultura e suas fontes}

Inovação é um processo interativo e envolve articulações entre diferentes agentes. No agronegócio existem inúmeras possibilidades, haja vista a extensão dessa cadeia produtiva (MAPA, 2010). O processo de inovação tecnológica na agricultura é um elemento que liga os meios de produção e seus diferentes agentes. Contribui positivamente no aumento da capacidade de produção de quem a utiliza (SANTOS, 2012).

Em relação às diversas fontes de inovações para a agricultura, Possas, Salles-Filho e Silveira, (1994) classificam em seis grupos principais as instituições de apoio à agricultura em relação ao seu desempenho na geração e difusão de inovações. As fontes e sua caracterização podem ser visualizadas no quadro 1.

Quadro 1 - Principais fontes de inovações para a agricultura

\begin{tabular}{|c|c|}
\hline Tipos & Competência \\
\hline $\begin{array}{l}\text { Fontes privadas de } \\
\text { organizações } \\
\text { industriais de } \\
\text { mercado }\end{array}$ & $\begin{array}{l}\text { Objetivam produzir e vender produtos intermediários e máquinas para os mercados } \\
\text { agrícolas, dentre as quais destacam as indústrias de máquinas e equipamentos (tratores } \\
\text { e implementos agrícolas e também irrigação), indústria de sementes, fertilizantes, } \\
\text { defensivos etc. }\end{array}$ \\
\hline $\begin{array}{l}\text { Fontes públicas } \\
\text { institucionais }\end{array}$ & $\begin{array}{l}\text { Buscam ampliar o conhecimento científico por meio de atividades de pesquisa básica, } \\
\text { desenvolvimento e melhoramento de tecnologias e produtos agrícolas e o } \\
\text { estabelecimento e transferência de práticas agrícolas mais eficientes. Fazem parte desse } \\
\text { grupo as universidades, instituições de pesquisa e empresas públicas de pesquisa. }\end{array}$ \\
\hline $\begin{array}{l}\text { Fontes privadas } \\
\text { vinculadas à } \\
\text { agroindústria }\end{array}$ & $\begin{array}{l}\text { Difundem tecnologia que produz benefícios nos estágios de processamento industrial. } \\
\text { As indústrias à jusante geram e difundem novas tecnologias, interferindo direta ou } \\
\text { indiretamente na produção dos produtos primários para beneficiar os estágios } \\
\text { subsequentes de processamento industrial; nesse grupo estão as indústrias de } \\
\text { transformação dos produtos agrícolas que interferem direta ou indiretamente na } \\
\text { produção de matéria-prima. }\end{array}$ \\
\hline $\begin{array}{l}\text { Fontes privadas, } \\
\text { organizadas } \\
\text { coletivamente e sem } \\
\text { fins lucrativos }\end{array}$ & $\begin{array}{l}\text { Organizações que desenvolver e transferem, de forma remunerada ou não, os insumos e } \\
\text { práticas agrícolas, tais como novos métodos de plantio, adubação, variedades de } \\
\text { sementes, métodos de controles de pragas, dentre outros. Em alguns mercados } \\
\text { específicos possuem uma ampla capacidade de influenciar os padrões competitivos. } \\
\text { Incluem cooperativas e associações de produtores. }\end{array}$ \\
\hline $\begin{array}{l}\text { Fontes privadas } \\
\text { relacionadas a } \\
\text { serviços de suporte } \\
\text { para a atividade } \\
\quad \text { agrícola }\end{array}$ & $\begin{array}{l}\text { Grupo em sua maior parte formado por divulgadores de tecnologia. Suas vantagens } \\
\text { competitivas normalmente focam o desenvolvimento de competências específicas e na } \\
\text { quantidade e qualidade de informações que a empresa é capaz de processar. Integram } \\
\text { essas fontes empresas que vendem serviços de suporte técnico, planejamento e gestão } \\
\text { da produção e serviços relacionados à produção de grãos, colheita e armazenamento e } \\
\text { reprodução animal. Dois tipos básicos são encontrados: a) empresas que vendem } \\
\text { assistência à agricultura planejamento; e b) as empresas que vendem serviços técnicos } \\
\text { especializados. }\end{array}$ \\
\hline & Incorporam o novo conhecimento por meio de um processo de aprendizado, que pode \\
\hline
\end{tabular}




\begin{tabular}{|c|l|}
\hline Unidades de & $\begin{array}{l}\text { resultar em inovações. O conhecimento tácito desenvolvido pelos agricultores, afeta } \\
\text { produçãficativamente o grau de cumulatividade e a capacidade tecnológica dos mesmos. } \\
\text { Quanto maior a quantidade de conhecimento, maior será o acúmulo de capacidade } \\
\text { tecnológica. }\end{array}$ \\
\hline
\end{tabular}

Fonte: adaptado de Possas, Salles-Filho e Silveira (1994).

Considerando as fontes de inovação citadas no quadro 1, Possas, Salles-Filho e Silveira (1994) destacam que se torna difícil quantificar de forma precisa a importância a ser atribuída a cada um dos seis grupos citados. Porém, há certa predominância dos primeiro e segundo grupo: as indústrias a montante e os centros de pesquisa públicos, sendo estes os dois polos a partir dos quais o regime tecnológico vigente na agricultura foi desenvolvido, ou seja, as atividades agropecuárias possuem um regime tecnológico com predomínio de empresas à montante juntamente com as instituições públicas de pesquisa.

Em relação às tecnologias inovadoras, o Brasil dispõe delas para a maioria das culturas básicas, produção de animais e agricultura tropical em geral. Das práticas inovadoras desenvolvidas, em destaque estão as adotadas na melhoria da fertilidade do solo como o plantio direto responsável pelo aumento da produtividade em $50 \%$ e a redução da erosão em 95\%; a adubação verde que diminui os custos com fertilizantes e evita os efeitos da erosão; a correção do solo com calcário ou gesso que aumenta a resistência à seca e permitiu aumentos de produtividade (soja 38\%, feijão 54\%, arroz 14\%, milho 13\%), e ainda as máquinas e equipamentos para plantio e colheita (ANTONIAZZI et al., 2013).

As inovações introduzidas na agricultura podem ainda ser agrupadas, de forma mais agregada, como "mecânicas" que poupam mão-de-obra ou "inovações bioquímicas" poupadoras de terra (SOUZA, 2005). Já na classificação de Silva (1990), elas constituem quatro grupos, comtemplando também os tipos anteriores:

(a) Inovações mecânicas geram impacto na intensidade e ritmo de trabalho;

(b) Inovações físico-químicas, responsáveis por transformar as condições naturais do solo, aumentando a produtividade e reduzindo as percas;

(c) Inovações biológicas, que impactam o giro do capital por reduzirem o período de produção/potencialização dos efeitos das inovações mecânicas e físico-químicas, envolvem melhoramentos genéticos;

(d) Inovações agronômicas, que garantem novos métodos de organizar a produção por meio da recombinação dos recursos disponíveis, resultando no aumento da produtividade de um sistema produtivo, sem implicar no uso de novos insumos ou produtos (manejo de solo, formas de plantio etc); são indispensáveis para o sucesso ou fracasso das demais inovações. 
No que se refere ao sistema de produção da soja, este foi totalmente revolucionado nas últimas três décadas caracterizado pela geração de tecnologias, consolidando o Brasil como segundo maior produtor mundial do grão, com perspectiva chegar à liderança global. Há dificuldade em citar todas as tecnologias que fizeram a diferença neste período sem que haja omissões, no entanto, Gazzoni (2013) destaca aquelas que permitem diferenciação em relação ao período anterior e cita: (a) plantio direto, (b) Cultivares adequadas às condições brasileiras, (c) zoneamento de risco agroclimático, (d) correção e adubação do solo, (e) manejo de pragas da soja e plantas daninhas, (f) mecanização agrícola, (g) múltiplas safras anuais e (h) integração lavoura, pecuária e floresta.

Dentre as tecnologias inovadoras supracitadas para a soja, Antoniazzi et al. (2013) elencaram grupos considerados de "tecnologias campeãs", por apresentaram maior impacto em produtividade e produção no Brasil e assim destacam: (a) inoculante para soja, (b) correção de solo, (c) sistema plantio direto, (d) desenvolvimento e uso de cultivares melhoradas, (e) manejo integrado de pragas e (f) zoneamento agroclimático.

A figura 1 ilustra o cenário relacionado ao conhecimento produzido para a agricultura conforme discutido até aqui. A dinâmica a cerca da produção de conhecimento/tecnologia para o setor tem seu ponto de partida o SNPA, o qual pode dar origem/suporte a uma diversidade de fontes para inovar, das quais derivam alguns tipos de transformações forma genérica. De forma mais específica, ou seja, derivada de todo esse contexto, surgem inovações direcionadas a um produto, no caso citou-se a soja. 
Figura 1 - Inovação na agricultura em seus diferentes níveis

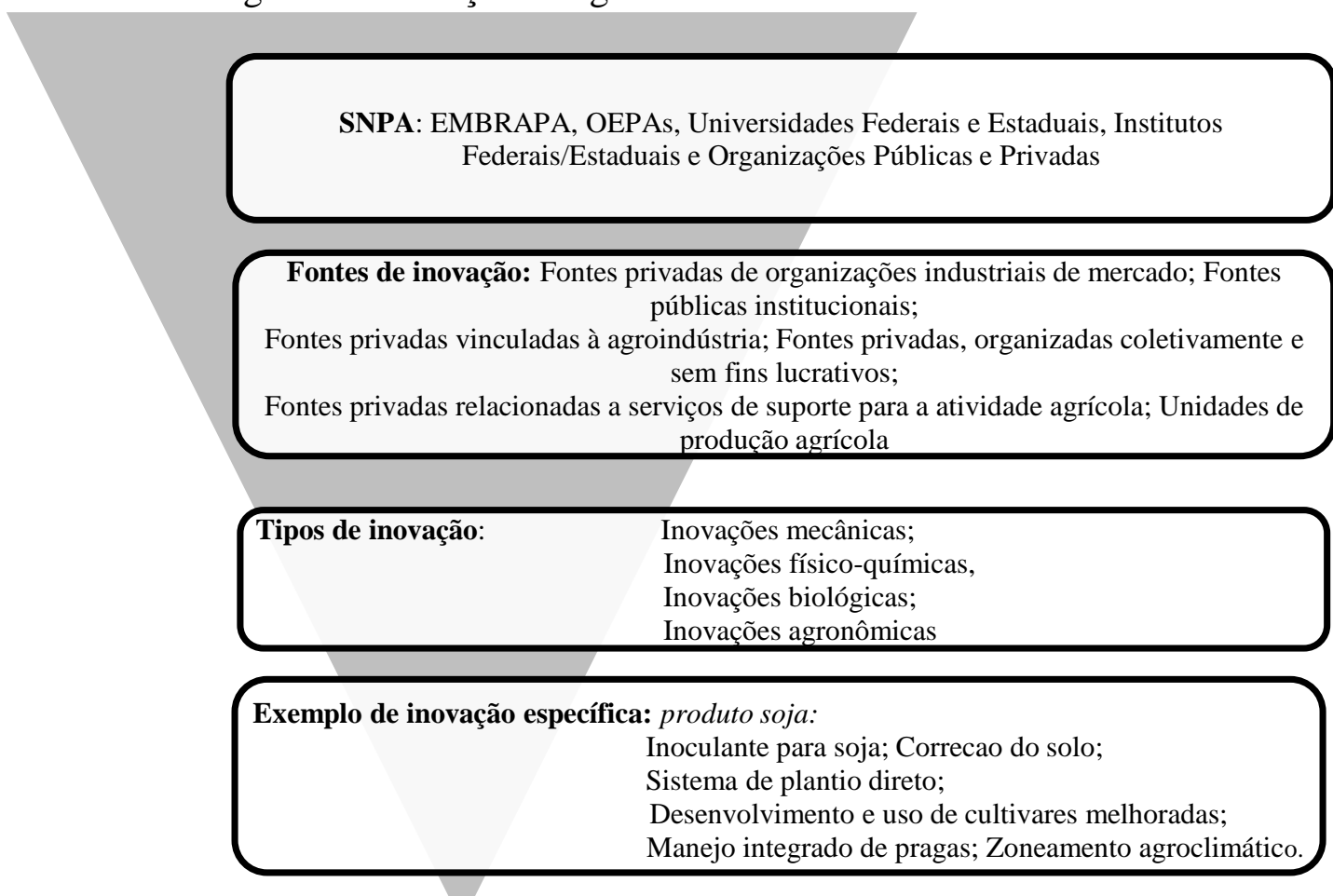

Fonte: elaborado pela autora (2016)

\section{METODOLOGIA}

Considerando a cadeia produtiva do agronegócio da soja (Fig. 2), os dados coletados sobre conhecimento para o agronegócio da soja se referem às entradas do processo de produção, as quais se traduzem em tecnologias necessárias ao processo produtivo. Compreendem fornecedores de sementes, fertilizantes, defensivos e máquinas, tecnologias/conhecimento especializado gerado pelo SNPA, recursos humanos e financeiros e ainda os consultorias agronômicas (enquadrados como "outros"), grupos estes que tem relação com os produtores e, portanto, se constituem fontes de conhecimento para o cultivo do grão (quadro 2). 
Figura 2 - Cadeia produtiva do agronegócio da soja

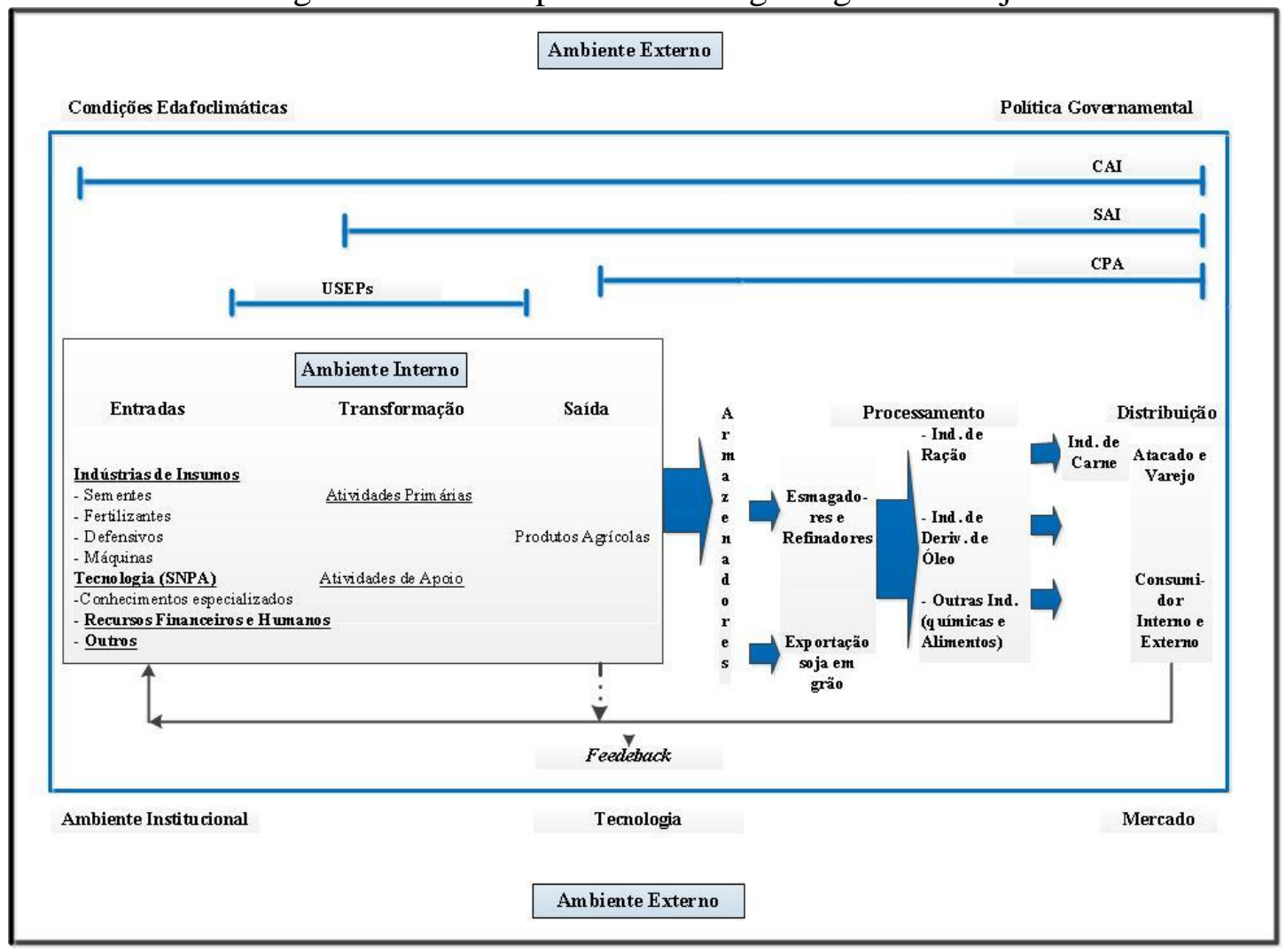

Fonte: Elaborado pela autora (2015) com adaptações de Porter (1989), Batalha e Silva (2012),

Lourenzzani (2005), Buainaim, Vieira e Vieira Junior (2006) e Lazzarini e Nunes (2000).

Como fora mencionado, o quadro 2 apresenta o grupo considerado como fontes de conhecimento/tecnologia para o agronegócio da soja, por esse motivo foram objeto da pesquisa, os quais são citados e caracterizados.

Quadro 2 - Agentes responsáveis pelas “entradas” considerados fontes de conhecimento/tecnologia para o agronegócio da soja

\begin{tabular}{|c|c|}
\hline $\begin{array}{c}\text { Fontes de } \\
\text { conhecimento/tecnologia }\end{array}$ & Fornecedores de entradas: indústria de Insumos \\
\hline $\begin{array}{c}\text { Fornecedores de } \\
\text { sementes }\end{array}$ & $\begin{array}{c}\text { Dois engenheiros agrônomos: um deles atende área de 1.200.000 mil hectares } \\
\text { em 7 municípios mato-grossenses; }\end{array}$ \\
$\begin{array}{c}\text { Outro também engenheiro e agrônomo e fitotecnista há mais de } 30 \text { anos na } \\
\text { área e atende todo o Estado. }\end{array}$ \\
\hline $\begin{array}{c}\text { Fornecedores de } \\
\text { máquinas }\end{array}$ & $\begin{array}{c}\text { Duas empresas do setor, multinacionais de grande porte que lideram o } \\
\text { mercado nacional na venda de máquinas e equipamentos para agricultura. }\end{array}$ \\
\hline $\begin{array}{c}\text { Fornecedores de } \\
\text { defensivos }\end{array}$ & $\begin{array}{c}\text { Duas principais revendas: um supervisor de vendas e outro engenheiro } \\
\text { agrônomo e gerente comercial }\end{array}$ \\
\hline $\begin{array}{c}\text { Fornecedores de } \\
\text { fertilizantes químicos }\end{array}$ & $\begin{array}{c}\text { Duas revendas: uma com tradição de 15 anos no mercado. } \\
\text { E outra com mais de 20 anos de experiência na área de fertilizantes }\end{array}$ \\
\hline $\begin{array}{c}\text { Fornecedor de } \\
\text { fertilizantes orgânico }\end{array}$ & Único a oferecer produto orgânico na região \\
\hline $\begin{array}{c}\text { Fontes de } \\
\text { Fonhecimento/tecnologia }\end{array}$ & Carnecedores de conhecimento especializado (SNPA) \\
\hline
\end{tabular}




\begin{tabular}{|c|c|}
\hline $\begin{array}{l}\text { EMBRAPA } \\
\text { Agrosilvopastoril } \\
\text { SINOP-MT }\end{array}$ & Única unidade da EMBRAPA no Mato Grosso \\
\hline $\begin{array}{l}\text { Organização Estadual } \\
\text { de Pesquisa } \\
\text { Agropecuária (OEPA): } \\
\text { EMAPER-MT* }\end{array}$ & Única instituição pública no Estado \\
\hline $\begin{array}{c}\text { Universidades e } \\
\text { institutos Federais e } \\
\text { Estaduais (UNEMAT*, } \\
\text { UFMT*, IFMT*) }\end{array}$ & $\begin{array}{c}\text { Todas as IES públicas e cursos desde o nível técnico, graduação, mestrado e } \\
\text { doutorado }\end{array}$ \\
\hline \multicolumn{2}{|r|}{ Organizações públicas e privadas } \\
\hline $\begin{array}{c}\text { Fontes de } \\
\text { conhecimento/tecnologia }\end{array}$ & Caracterização da fonte de dados \\
\hline Fundação MT & Única intuição de pesquisa privada no Mato Grosso \\
\hline SENAR-MT* & $\begin{array}{l}\text { Única instituição que promove treinamentos gratuitos com foco na } \\
\text { agropecuária mato-grossenses }\end{array}$ \\
\hline UNIC* e UNIVAG* & Maiores IES privadas no Estado com cursos presenciais \\
\hline \multicolumn{2}{|r|}{ Recursos Humanos e financeiros } \\
\hline $\begin{array}{c}\text { Fontes de } \\
\text { conhecimento/tecnologia }\end{array}$ & Caracterização da fonte de dados \\
\hline Recursos Humanos & Comtemplado nas IES e SENAR-MT \\
\hline $\begin{array}{l}\text { Recursos financeiros de } \\
\text { fomento a aquisição de } \\
\text { tecnologias }\end{array}$ & $\begin{array}{c}\text { O Banco do Brasil é a instituição de o que mais financia o agronegócio no } \\
\text { Brasil. } \\
\text { Entrevista com o Consultor de negócios para o agronegócio }\end{array}$ \\
\hline & Outras fontes \\
\hline $\begin{array}{c}\text { Fontes de } \\
\text { conhecimento/tecnologia }\end{array}$ & Caracterização da fonte de dados \\
\hline Serviços de consultoria & $\begin{array}{l}\text { Duas maiores consultorias: uma agronômica e em gestão; outra só } \\
\text { agronômica }\end{array}$ \\
\hline
\end{tabular}

Fonte: elaborado pela autora (2016)

* Empresa Mato-grossense de Pesquisa, Assistência e Extensão Rural (EMPAER-MT)

* Universidade do estado de Mato Grosso (UNEMAT)

* Universidade Federal do estado de Mato Grosso (UFMT)

* Instituto Federal do Mato Grosso (IFMT)

* Universidade de Cuiabá (UNIC)

* Serviço nacional de Aprendizagem Rural de Mato Grosso (SENAR-MT)

* Centro Universitário de várzea grande (UNIVAG)

A busca de dados junto aos fornecedores de sementes, fertilizantes, defensivos e máquinas permitiu identificar as tecnologias oferecidas e acesso a elas, além do tipo de interação com produtores de soja. Assim, as revendas de sementes, fertilizantes, defensivos e máquinas foram indagadas quanto: ao tipo de produto/serviço comercializado; forma que interagem com o cliente (além da venda do produto, o quem mais oferece/disponibiliza) e produtos/serviços que estão por vir no segmento que atua a serem disponibilizados aos produtores. Os dados obtidos nas entrevistas foram complementados com informações disponíveis nos sites das empresas quando necessário.

No quesito conhecimento especializado: o SNPA, considerando a composição desse sistema, instituições de pesquisa vinculadas à atividade de pesquisa agropecuária, a nível de Mato Grosso que o integram e para tanto foram abordadas, as seguintes: EMBRAPA 
Agrossilvipastoril, EMPAER-MT, UFMT, UNEMAT, IFMT, Fundação MT, SENAR-MT, UNIC e UNIVAG. O mapeamento dessas instituições e o conhecimento produzido direcionado ao agronegócio da soja se deu com base na consulta em sua páginas na internet, bem como contato por e-mails, telefone para complementar as informações quando necessário. Foram citados todos os cursos oferecidos em seus diferentes níveis de formação vigentes em 2015 com foco no agronegócio. Esses dados permitiram desenhar, em termos de forma e conteúdo, a configuração do SNPA no Mato Grosso.

Ainda como "entradas", ou seja, recursos necessários ao processo de produção agrícola estão os recursos humanos e financeiros. A contribuição em termos de conhecimento especializado (fator humano), foram elencados os cursos de capacitação oferecidos no Estado e disponíveis para a região. Foi considerado desde cursos de curta duração, técnicos, tecnólogos, graduação e pós lato e strictu sensu que tivessem conteúdo voltado a formação de recursos humanos para trabalharem nas unidades de produção (dentro da porteira). Nesse quesito foram consideradas para fins de análise o que já fora comtemplado no SNPA, ou seja, as IES (UFMT, UNEMAT, IFMT, UNIC e UNIVAG) e SENAR-MT.

Em relação aos recursos financeiros necessários ao processo de produção, mesmo não sendo fontes de transferência de conhecimento, mas pelo fato de poderem interferir (pois no passado políticas de crédito fomentaram a adoção de novas tecnologias) isso foi alvo de análise. Para tanto, foi realizada entrevista com um consultor de negócios para o agronegócio num dos bancos que se destaca pelo volume de financiamentos ao agronegócio. Na entrevista semiestruturada, sempre considerando a produção de soja, abordou-se questões envolvendo: a) tipos de créditos para o agronegócio; b) linha do Programa de Incentivo à Inovação Tecnológica na Produção (INOVAGRO) e c) acesso as linhas de crédito.

Por fim, sobre as fontes de conhecimento/tecnologia, para o item denominado “outros", foram abordados consultores que atuam juntos aos sojicultores nas áreas de gestão e agronômica, sendo então contatadas duas consultorias localizadas, como os demais agentes, no município de Tangará da Serra-MT.

Por fim, foram realizadas observações a campo. Para tanto, considerou-se também como fonte/transferência de conhecimento acontecimentos como palestras, simpósios e Dia de Campo. A coleta de dados envolveu a participação em eventos promovidos por entidades de pesquisa (FMT), consultoria agronômica e de pesquisa agrícola (Agrodinâmica), de representação (APROSOJA-MT) e de ensino (UNEMAT). Esses momentos objetivam a difusão de tecnologia para a agricultura, na forma de resultados de pesquisas ou debates com temas de interesse, especialmente da soja, principal produto cultivado em Mato Grosso. O 
espaço temporal acompanhado compreendeu os meses de agosto de 2015 a fevereiro de 2016, período que coincide com o ciclo que vai do preparo do solo a colheita da soja.

Os municípios em que as observações foram feitas, envolveu, além de Tangará da Serra-MT, Campo Novo do Parecis-MT, Nova Mutum- MT, Sorriso-MT, e RondonópolisMT, sendo o último sede da FMT.

\section{ANÁLISE E DISCUSSÃO DOS DADOS}

Nesse item são apresentados dados sobre as fontes de conhecimento/tecnologia para agronegócio da soja com base na sua cadeia de produção (Fig. 3), os quais consideraram as “entradas" para o processo produtivo desse grão, como já destacado no item 3 deste trabalho.

\subsection{SNPA como fonte de inovação e/ou conhecimento e sua configuração no Mato Grosso}

Conforme o mostrado na figura 3, integram o SNPA, em âmbito federal a EMBRAPA. Essa instituição se destaca na geração, adaptação e transferência de conhecimentos e tecnologias, representados por novas cultivares, que foi em muitos casos catalisados pela indústria privada produtora de insumos para a agricultura. Sua atuação no Brasil permitiu, dentre outros, que a região centro-oeste se transformasse numa das maiores fronteiras agrícolas mundiais (VIEIRA FILHO; CAMPOS; FERREIRA, 2005).

Geograficamente está distribuída em 17 unidades centrais localizadas em Brasília e 46 unidades descentralizadas em todas as regiões do Brasil. Dentre as quais está a EMBRAPA Cerrados, criada em 1975 para viabilizar a produção agrícola no Cerrado brasileiro. Suas ações envolvem atividades de pesquisa e desenvolvimento para ampliar o conhecimento, a preservação e a utilização racional dos recursos naturais do Bioma Cerrado. As tecnologias criadas transformaram o Cerrado numa das maiores fronteiras agrícolas do mundo e referência internacional em produtividade (EMBRAPA CERRADOS, 2015).

Também no Centro Oeste, no município de Sinop-MT, está localizada outra unidade da EMBRAPA, a Agrossilvipastoril criada em 2009. Seus trabalhos tem foco nas inovações tecnológicas para os sistemas integrados de produção agropecuária e para as principais cadeias produtivas representativas no Estado. Para tanto, dispõe de pesquisadores com diferentes especialidades, trabalhando com temas como: manejo integrado de pragas, doenças e plantas daninhas, dinâmica de carbono, emissões de gases de efeito estufa, agricultura de precisão, manejo e restauração florestal, produção animal, manejo de pastagem, dentre outros.

Outras entidades integrantes do SNPA são as OEPAs, presentes em todas as regiões brasileiras: Nordeste, Sudeste, Sul, Norte e Centro-Oeste. Como exemplo local cita-se a 
instituição estadual de pesquisa, a EMPAER-MT. É uma empresa pública e atua nos 141 municípios do Estado do Mato Grosso ofertando de serviços de assistência técnica e extensão rural, pesquisa e fomento aos agricultores familiares (EMPAER-MT, 2015).

Integram ainda esse sistema, instituições de ensino como universidade e institutos federais e estaduais. Em nível de Mato Grosso, estão a UFMT, instituída no estado em 1970, a UNEMAT criada em 1993 e o IFMT estabelecido em 2008. Essas entidades se fazem presentes em diversos municípios do Mato Grosso e por desenvolverem ensino, pesquisa e extensão, com foco na agricultura, contribuem para o SNPA. Observa-se a frequência do curso de agronomia (comum a todas), no entanto os de pós-graduação stricto senso é ofertado somente por duas IES públicas (UFMT e UNEMAT). No quadro 3 podem ser visualizados os cursos técnicos, tecnólogo, de graduação e pós-graduação - lato e strictu sensu - ofertados pelas IES.

Quadro 3 - IES no MT e os cursos voltados a agricultura nos diferentes níveis em 2015

\begin{tabular}{|c|c|}
\hline Pós-Graduação & IES \\
\hline \multicolumn{2}{|l|}{ DOUTORADO } \\
\hline Programa de pós-graduação em agricultura tropical & UFMT \\
\hline \multicolumn{2}{|l|}{ MESTRADO } \\
\hline Pós-graduação em genética e melhoramento de plantas (PGMP) & UNEMAT \\
\hline $\begin{array}{l}\text { Pós-graduação interdisciplinar em ambiente e sistema de produção agrícola } \\
\text { (PPGASP) }\end{array}$ & UNEMAT \\
\hline Programa de pós-graduação em agronegócios e desenvolvimento regional & UFMT \\
\hline Programa de pós-graduação em agricultura tropical & UFMT \\
\hline \multicolumn{2}{|l|}{ PÓS - GRADUAÇÃO LATO SENSU } \\
\hline MBA em Gestão do Agronegócio & UNIC e UNIVAG \\
\hline \multicolumn{2}{|l|}{ CURSOS GRADUAÇÃO } \\
\hline Agronomia & $\begin{array}{l}\text { UFMT, UNEMAT, UNIC, } \\
\text { UNIVAG e IFMT }\end{array}$ \\
\hline Zootecnia & UFMT, UNEMAT e IFMT \\
\hline Engenharia de Produção Agroindustrial & UNEMAT \\
\hline Administração com linha de formação em Agronegócio & UNEMAT \\
\hline Gestão Estratégica do Agronegócio & UNIC \\
\hline Agronegócios & UNIC \\
\hline Licenciatura em Ciências Agrícolas & IFMT \\
\hline CURSOS TECNÓLOGOS & IES \\
\hline Técnico em Agropecuária & IFMT \\
\hline Tecnologia em Agronegócios & UNIC e UNVAG \\
\hline Tecnólogo em Alimentos & UNIVAG \\
\hline
\end{tabular}

Fonte: Elaborado pela autora (2015)

O quadro 3 citou as atividades de ensino, no entanto faz parte da atuação das universidades realizarem atividades de pesquisa e extensão. Nesse sentido foi identificado o foco dos projetos vigentes em 2015. Constatou-se que as atividades de pesquisa e extensão com foco na agricultura e temáticas afins são realizadas somente pelas IES públicas, no caso UFMT, IFMT e UNEMAT, conforme mostrado no quadro 4. 
Quadro 4 - Abordagem dos projetos de pesquisa e extensão realizados pelas IES públicas em Mato Grosso

\begin{tabular}{|c|l|}
\hline \multicolumn{1}{|c|}{ IES } & \multicolumn{1}{c|}{ Cultivos e temáticas abordados nos projetos de pesquisa e/ou extensão } \\
\hline UFMT & $\begin{array}{l}\text { - Solo, adubação, perdas na colheita, qualidade da semente, irrigação e armazenagem; } \\
\text { - Cultivo da soja e milho. }\end{array}$ \\
\hline IFMT & $\begin{array}{l}\text { - Solos, adubação, controle de pragas, recuperação de pastagens, uso de herbicida; } \\
\text { - Cultivo de girassol, soja, milho, trigo, hortigranjeiros, tectona, dendê e mamona. leite e carne } \\
\text { ovina. }\end{array}$ \\
\hline UNEMAT & $\begin{array}{l}\text { - Estratégia de produção dos sojicultores, viabilidade econômica, gestão de propriedades rurais } \\
\text { (familiares), assimilação de tecnologias no agronegócio, agroecologia e desenvolvimento rural, } \\
\text { agricultura familiar, sistemas produtivos, gases de efeito estufa, diversificação e consórcio de } \\
\text { lavouras, lógicas e sistemas de produção, reforma de pastagens, perdas na colheita, inspeção de } \\
\text { máquinas agrícolas (tratores). } \\
\text { - Cultivo de milho, mandioca, abacaxi, cana de açúcar, hortaliças, soja. }\end{array}$ \\
\hline
\end{tabular}

Fonte: Elaborado pela autora (2015)

Dentre as organizações públicas e/ou privadas que compõem esse sistema, cita-se a FMT criada em 1993. Inicialmente suas atividades eram realizadas em pareceria com a EMBRAPA que não possuía uma unidade de pesquisa em Mato Grosso. Depois de sete anos dando suporte para as pesquisas oficiais, a FMT se tornou independente. Atualmente direciona seus trabalhos para Mato Grosso e uma nova divisão foi criada a Tropical Melhoramento \& Genética (TMG), desde 2009/10 responsável pela genética de cultivares como soja e algodão. A TMG desenvolve cultivares de soja convencionais e transgênicas e variedades de algodão, para atender as demandas dos produtores (FMT, 2015).

Os trabalhos de pesquisa que a FMT realiza tem foco na área de proteção de plantas e também em manejo e adubação de solo. Boa parte desses estudos é realizada em duas estações de pesquisa e, posteriormente os resultados são difundidos pelos pesquisadores aos produtores do Estado do Mato Grosso. A difusão tecnológica é contínua e envolve eventos de acordo com o calendário agrícola da soja e algodão: Dia de Campo, encontro técnico e reuniões. Além dos eventos, leva informações aos produtores através de Boletim de Pesquisa de Soja, boletins de cultivares, informativos técnicos de algodão, boletins informativos e por meio do endereço eletrônico (FMT, 2015).

Citam-se ainda como instituições privadas duas IES que oferecem formação profissional com cursos direcionados ao contexto agrícola. Uma dessas é a UNIVAG, fundada em 1989 e tem sede e campus único localizado na cidade de na Várzea Grande-MT. E a outra é a UNIC, fundada em 1988 e conta com 11 campi no Estado. Essas IES ofertam cursos de nível tecnólogo, graduação e pós-graduação lato sensu, os quais foram citados no quadro 3.

E por fim, como instituição pública tem-se o SENAR-MT. Criado em 1991, é uma entidade de direito privado, mantida pela classe patronal rural, vinculada à Confederação da Agricultura e Pecuária do Brasil (CNA). 
Como instituição de ensino rural, voltada para produtores, trabalhadores rurais e seus familiares, o SENAR-MT realiza treinamentos e capacitações. Em 2015 disponibilizava 234 treinamentos voltados para Formação Profissional Rural (FPR) ou Promoção Social (PS).

As ações realizadas são gratuitas e seu portfólio de treinamentos é voltado às demandas das 15 principais cadeias produtivas de Mato Grosso, dentre as quais Sojicultura e Milhocultura (soja e milho), Cotonicultura (algodão) e Bovinocultura de Corte (carne bovina).

Os dados levantados permitiram caracterizar o SNPA no Mato Grosso, que a apresenta de forma sintetizada o apresentado na Figura 3. Observa-se como citado por Muteia (2011) e Santos (2012), Vieira filho 2012; Vieira Filho; Campos; Fereira, 2005 um quadro institucional brasileiro, público e privado favorável à pesquisa e desenvolvimento agrícola, capaz de produzir conhecimento para atender demandas agrícolas.

Se o Mato Grosso nas últimas safras se destaca como maior produtor brasileiro do grão, esse status evidencia o importante papel dessas instituições. Nesse sentido, é pertinente destacar, embora não fosse objeto de estudo nesta pesquisa, a atuação do produtor, como mencionam Vieira Filho e Silveira (2012) e Vieira Filho e Pinto Vieira (2013), pela sua capacidade de incorporar de forma contínua novas tecnologias na agricultura.

Figura 3 - SNPA e sua configuração no Mato Grosso

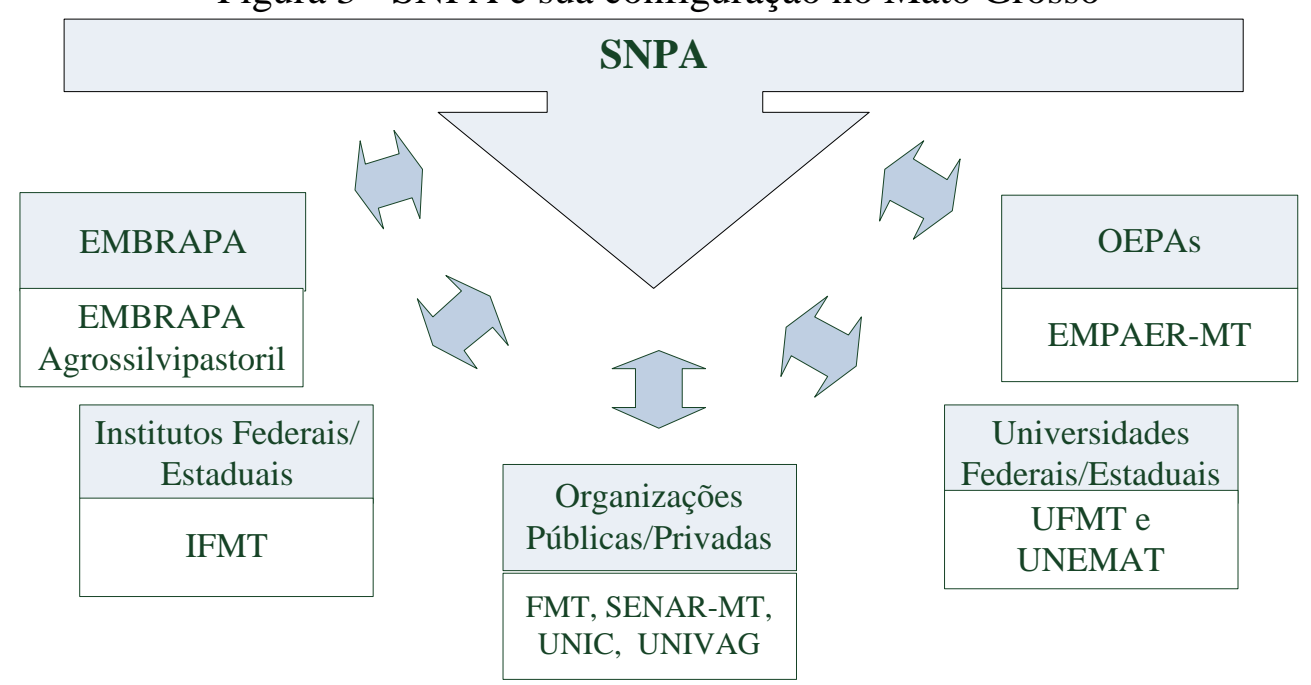

Fonte: Elaborado pela autora (2016)

\subsection{Fontes de conhecimento/tecnologia e sua transferência}

O quadro 5 reúne os principais aspectos referentes às fontes, tipos de conhecimento para o agronegócio da soja e o modo como esses agentes interagem com os produtores. De forma geral, constatou-se uma interação contínua das revendas, derivado dos serviços de vendas e pós-vendas, pois acompanha o ciclo da soja e se estende no caso de outros cultivos, 
desde que haja aquisições de insumos. Esses contatos envolvem visitas às propriedades, treinamentos diversos, Dia de Campo, entregas técnicas, experimentos, dentre outros.

Já no grupo integrado pelas intuições que compõem o SNPA a dinâmica de contatos comtempla capacitações continuadas, implantação de Unidades de Referência Tecnológica e Econômica (URTEs), Dia de campo (EMBRAPA Agrossilvipastoril), visitas a pequenos e médios produtores, testes com produtos (EMPAER-MT), ensino, pesquisa, extensão e palestras (IES), treinamentos em diversas áreas (SENAR-MT) e novamente Dia de Campo, encontros técnicos, palestras e boletim de pesquisa (FMT). Percebe-se nesse grupo, que diferente do anterior, embora exista interação na difusão de conhecimento, boa parte resultado de pesquisas que desenvolvem isso ocorre de forma mais pontual e não tem a proximidade e continuidade observada nas revendas.

Ainda como fontes de conhecimento, há os recursos humanos (já citados anteriormente em termos de capacitações disponíveis) e os recursos financeiros. Quanto aos últimos, considerou-se a linha de crédito para o Programa de Incentivo à Inovação Tecnológica na Produção Agropecuária (INOVAGRO), por entender que o crédito, de forma indireta, pode ser fonte de inovação pelo fato de fomentar a transferência de tecnologia. Nesse quesito contatou-se, mediante entrevista com o agente responsável por esse crédito num banco local, que essa linha de credito para investimento, é pouco acessada, o que ele atribui ao desconhecimento por parte dos produtores de soja.

E por fim, no grupo fornecedores de conhecimentos enquadrados como "outros", estão as consultorias agronômicas e de gestão, A Atuação delas envolve visitas semanais aos produtores, treinamentos e Dia de campo. No entanto, esse contato é restrito, pois atendem somente aos que contratam serviços. Inclusive umas das consultorias realiza Dia de Campo e não abre ao público em geral, somente a convidados.

Quadro 5 - Resumo das fontes consultadas e como transferem conhecimento

\begin{tabular}{|c|c|c|}
\hline \multicolumn{3}{|c|}{ Fornecedores de entradas: indústria de Insumos } \\
\hline $\begin{array}{c}\text { Fontes de } \\
\text { conhecimento }\end{array}$ & Tipos & Como transferem \\
\hline $\begin{array}{c}\text { Fornecedores de } \\
\text { sementes }\end{array}$ & $\begin{array}{c}\text { Genética; orientações sobre o tipo de } \\
\text { sementes, cuidados na armazenagem e } \\
\text { plantio }\end{array}$ & $\begin{array}{l}\text { - Contatos por telefone; } \\
\text { - Visitas as propriedades (vendas e pós } \\
\text { venda) no período que antecede o plantio } \\
\text { até a germinação. }\end{array}$ \\
\hline Fornecedores de & $\begin{array}{c}\text { Adequação dos equipamentos a } \\
\text { realidade do produtor; usos dos recursos } \\
\text { tecnológicos embutidos nas máquinas e } \\
\text { equipamentos. }\end{array}$ & $\begin{array}{l}\text { - Visitas constantes aos produtores (venda e } \\
\text { pós venda) } \\
\text { - Treinamentos sobre o uso de máquinas e } \\
\text { equipamentos e agricultura de precisão; } \\
\text { - "Entrega Técnica": orientações pelo } \\
\text { mecânico quanto ao funcionamento de }\end{array}$ \\
\hline
\end{tabular}




\begin{tabular}{|c|c|c|}
\hline máquinas & & $\begin{array}{l}\text { máquinas equipamentos na entrega do } \\
\text { produto; } \\
\text { - "Dia de compra": Encontros nas revendas } \\
\text { para lançamentos de novos produtos; } \\
\text { - "Dia de Campo": demonstrações técnicas } \\
\text { in loco sobre o uso de um novo produto ou } \\
\text { melhorado. }\end{array}$ \\
\hline $\begin{array}{c}\text { Fornecedores de } \\
\text { defensivos }\end{array}$ & $\begin{array}{c}\text { Orientações quanto aos defensivos a } \\
\text { serem utilizados desde o plantio até a } \\
\text { colheita: tipos de produtos, dosagens, } \\
\text { necessidade de aplicação, regulagem de } \\
\text { equipamentos, testes de produtos a } \\
\text { serem lançados. } \\
\end{array}$ & $\begin{array}{l}\text { - Visitam produtores e também produtores } \\
\text { visitam a revenda (serviços de venda e pós } \\
\text { venda durante o ciclo da soja); } \\
\text { - Treinamentos } \\
\text { - Dia de Campo }\end{array}$ \\
\hline $\begin{array}{l}\text { Fornecedores de } \\
\text { fertilizantes } \\
\text { químicos }\end{array}$ & $\begin{array}{l}\text { Com base nas análises de solo, são } \\
\text { fornecidas as quantidades de } \\
\text { fertilizantes/adubos, os quais podem ser } \\
\text { foliares ou de solo, responsáveis pelo } \\
\text { aumento da produtividade. }\end{array}$ & $\begin{array}{l}\text { - Visitam as propriedades para } \\
\text { acompanhamento durante o cicio da soja } \\
\text { (venda e pós venda); } \\
\text { - Fazem experimentos com testes de } \\
\text { produtos } \\
\text { - Estabelecem parcerias com os agrônomos } \\
\text { das propriedades - multiplicadores; } \\
\text { - Produtores procuram a revenda. }\end{array}$ \\
\hline $\begin{array}{l}\text { Fornecedor de } \\
\text { fertilizantes } \\
\text { orgânico }\end{array}$ & $\begin{array}{l}\text { Fornece material (matriz) tanque e filtro } \\
\text { para implantação da bio fábrica de } \\
\text { adubo orgânico na propriedade rural }\end{array}$ & $\begin{array}{l}\text { - Visitas as propriedades para orientações } \\
\text { acompanhamento técnico quanto instalação } \\
\text { e manutenção (venda e pós venda); } \\
\text { - Treinamento quanto a formulação e uso } \\
\text { de produto. }\end{array}$ \\
\hline \multicolumn{3}{|c|}{ Fornecedores de conhecimento especializado (SNPA) } \\
\hline $\begin{array}{c}\text { Fontes de } \\
\text { conhecimento }\end{array}$ & Tipos & Como transferem \\
\hline $\begin{array}{c}\text { EMBRAPA } \\
\text { Agrosilvopastoril } \\
\text { SINOP-MT }\end{array}$ & $\begin{array}{l}\text { Desenvolve pesquisas com foco na } \\
\text { integração Lavoura e Pecuária e Floresta } \\
\text { (ILPF) considerando as principais } \\
\text { cadeias produtivas no Estado }\end{array}$ & $\begin{array}{l}\text { - Capacitação continuada de agentes de } \\
\text { assistência técnica e extensão rural do setor } \\
\text { público e privado (multiplicadores) via } \\
\text { cursos modulares; } \\
\text { - Implantação de URTEs para a capacitação } \\
\text { de produtores e técnicos pelos } \\
\text { multiplicadores comtemplando dez cadeias } \\
\text { produtivas. } \\
\text { - - Dia de Campo }\end{array}$ \\
\hline $\begin{array}{c}\text { OEPA: } \\
\text { EMAPER-MT }\end{array}$ & $\begin{array}{l}\text { Assistência técnica, pesquisa e extensão } \\
\text { rural; elaboração de projetos agrícolas } \\
\text { direcionados a agricultores familiares } \\
\text { (pequenos e médios) }\end{array}$ & $\begin{array}{l}\text { - Visitam as propriedades rurais e também } \\
\text { atendem os produtores no escritório; } \\
\text { - Fazem testes com novas variedades de } \\
\text { cultivares (feijão, milho) em parceria com a } \\
\text { EMBRAPA; os resultados destes e demais } \\
\text { pesquisas, orientam as atividades de } \\
\text { extensão que realizam. }\end{array}$ \\
\hline $\begin{array}{l}\text { Universidades e } \\
\text { institutos } \\
\text { Federais e } \\
\text { Estaduais } \\
\text { (UNEMAT, } \\
\text { UFMT, IFMT) } \\
\end{array}$ & $\begin{array}{l}\text { Formação profissional de nível técnico } \\
\text { para agricultura (IFMT), agronomia e } \\
\text { áreas afins e aperfeiçoamento em nível } \\
\text { de pós-graduação lato e stricto sensu }\end{array}$ & $\begin{array}{l}\text { - Atividades de ensino, pesquisa e extensão; } \\
\text { - Realizam de eventos como palestras e } \\
\text { simpósios. }\end{array}$ \\
\hline \multicolumn{3}{|c|}{ Organizações públicas e privadas } \\
\hline $\begin{array}{c}\text { Fontes de } \\
\text { conhecimento }\end{array}$ & Tipos & Como transferem \\
\hline FMT & $\begin{array}{c}\text { Melhoramento genético em sementes } \\
\text { (TMG), pesquisa sobre adubação, solos } \\
\text { e agricultura de precisão }\end{array}$ & $\begin{array}{l}\text { - Realizam palestras que coincidem com o } \\
\text { ciclo da soja; } \\
\text { - Dia de campo; } \\
\text { - Encontros técnicos; } \\
\text { - Boletim de Pesquisa de Soja (bi anual, } \\
\text { material impresso); }\end{array}$ \\
\hline
\end{tabular}




\begin{tabular}{|c|c|c|}
\hline SENAR-MT & $\begin{array}{l}\text { Treinamentos voltados aos principais } \\
\text { cultivos agrícolas no estados (cursos de } \\
\text { curta duração) sob demanda dos } \\
\text { produtores }\end{array}$ & $\begin{array}{l}\text { - Realizam treinamentos voltados às } \\
\text { demandas das } 15 \text { principais cadeias } \\
\text { produtivas de Mato Grosso, conforme a } \\
\text { demanda dos produtores e em todos os } \\
\text { municípios do estado. }\end{array}$ \\
\hline $\begin{array}{l}\text { UNIC e } \\
\text { UNIVAG }\end{array}$ & $\begin{array}{c}\text { Formação profissional de nível } \\
\text { tecnológico, graduação e pós-graduação } \\
\text { lato senso } \\
\text {.. }\end{array}$ & - Atividades de ensino \\
\hline \multicolumn{3}{|c|}{ Recursos Humanos e financeiros } \\
\hline $\begin{array}{c}\text { Fontes de } \\
\text { conhecimento }\end{array}$ & Tipos & Como transferem \\
\hline $\begin{array}{l}\text { Recursos } \\
\text { Humanos }\end{array}$ & $\begin{array}{l}\text { Qualificação profissional para o } \\
\text { agronegócio }\end{array}$ & $\begin{array}{c}\text { - Já comtemplado via atividades das IES e } \\
\text { SENAR-MT }\end{array}$ \\
\hline $\begin{array}{l}\text { Recursos } \\
\text { financeiros de } \\
\text { fomento a } \\
\text { aquisição de } \\
\text { tecnologias }\end{array}$ & $\begin{array}{c}\text { Linhas de crédito para aquisição de } \\
\text { máquinas e equipamentos, bem como } \\
\text { melhorias nos processos de gestão } \\
\text { (INOVAGRO) }\end{array}$ & $\begin{array}{l}\text { - Fortalece o setor rural e incentiva a } \\
\text { introdução de métodos racionais no sistema } \\
\text { de produção; } \\
\text { - Na forma de apoio as aquisições } \\
\text { necessárias à incorporação de inovação } \\
\text { tecnológica nas propriedades rurais }\end{array}$ \\
\hline \multicolumn{3}{|c|}{ Outras fontes } \\
\hline $\begin{array}{c}\text { Fontes de } \\
\text { conhecimento }\end{array}$ & Tipos & Como transferem \\
\hline $\begin{array}{l}\text { Serviços de } \\
\text { consultoria }\end{array}$ & $\begin{array}{l}\text { Serviços agrimensura, assistência } \\
\text { técnica agronômica, assessoria na } \\
\text { compra de insumos para produção } \\
\text { equipamentos (dimensionamento de } \\
\text { frota adequada à realidade do produtor), } \\
\text { análise de solo e projetos para } \\
\text { financiamentos diversos e gestão nas } \\
\text { áreas de controle de custos, compras, } \\
\text { recrutamento e seleção, etc. }\end{array}$ & $\begin{array}{l}\text { - Visitam semanalmente as propriedades } \\
\text { para acompanhamentos técnico dos } \\
\text { projetos que realizam em volvendo } \\
\text { aspectos técnicos e agronômicos (no } \\
\text { período que antecede o plantio e segue até } \\
\text { o termino da segunda safra nos casos em } \\
\text { que esta é feita); } \\
\text { - Treinamentos sobre regulagem de } \\
\text { máquinas } \\
\text { - Dia de Campo (somente uma que realiza e } \\
\text { o evento é fechado). }\end{array}$ \\
\hline
\end{tabular}

Fonte: elaborado pela autora (2016)

Destaca-se ainda em relação ao quadro 5, de acordo com Possas, Salles-Filho e Silveira, (1994), que os sojicultores mato-grossenses têm acesso a quatro grupos principais de apoio à agricultura na geração e difusão de inovações: a) Fontes privadas de organizações industriais de mercado (revendas de insumos), b) Fontes públicas institucionais (EMBRAPA, Universidades, SENAR-MT, IFMT e EMPAER-MT), d) Fontes privadas, organizadas coletivamente e sem fins lucrativos (FMT, APROSOJA-MT), e) e) Fontes privadas relacionadas a serviços de suporte para a atividade agrícola (empresas de consultoria agronomia). Dos seis grupos, Possas, Salles-Filho e Silveira (1994) destacam a predominância das indústrias a montante (fornecedores de insumos) e os centros de pesquisa públicos, os quais foram percebidos neste estudo. 


\subsection{Transferência de conhecimento: eventos}

Os eventos realizados na forma de Dia de Campo, palestra ou simpósios voltados ao cultivo da soja, no período de agosto de 2015 a fevereiro de 2016, são apresentados no quadro 6, e acontecerem num espaço temporal que coincide com o ciclo da soja. Observa-se nesse quesito maior presença da FMT na oferta de eventos que são tradicionais no Estado. Destacase também a APROSOJA-MT, embora sendo uma entidade representativa, não de pesquisa, mesmo assim leva aos sojicultores conhecimento especializado buscado na FMT e também na EMBRAPA Soja do Paraná.

Quadro 6- Difusão de conhecimento em eventos e Dia de Campo

\begin{tabular}{|c|c|c|}
\hline $\begin{array}{l}\text { Instituição } \\
\text { promotora }\end{array}$ & $\begin{array}{c}\text { Denominação do } \\
\text { Evento }\end{array}$ & Conhecimentos difundidos \\
\hline \multirow{3}{*}{ FMT } & "É Hora de Plantar" & $\begin{array}{l}\text { - Adubação e aumento de produtividade; } \\
\text { - Previsões Climáticas: Impactos do El Ninõ para a safra 2015/16; } \\
\text { - Eficiência no manejo e controle de doenças }\end{array}$ \\
\hline & "É Hora de Cuidar" & $\begin{array}{l}\text { Tema central: Entendendo o manejo e controle na lavoura } \\
\text { - Manejo de pragas: controle e qualidade do produto final; } \\
\text { - Adjuvantes e formulações: entendendo o papel da calda na } \\
\text { tecnologia de aplicação; } \\
\text { - Cuidados e perspectivas sobre Ferrugem asiática. Chegou a hora } \\
\text { de decidir: nossa inimiga ou sócia? }\end{array}$ \\
\hline & $\begin{array}{l}\text { FMT em Campo } \\
\text { (realizado nas } \\
\text { estações de pesquisa } \\
\text { da FMT) }\end{array}$ & $\begin{array}{l}\text { Tema central: Produtividade e Rentabilidade } \\
\text { - Resultados de experimentos em } 21 \text { estacoes de pesquisa sobre } \\
\text { culturas soja, milho e algodão em temas como estádios de } \\
\text { dessecação da soja, efeitos da palha para a semeadura da soja, } \\
\text { compactação do solo, rotação de culturas, adubação, efeitos da } \\
\text { sub adubação, calagem e gessagem, arranjo espacial de plantas, } \\
\text { agricultura de precisão, controle de pragas, insetos e doenças, } \\
\text { avaliação de fungicidas, manejo de herbicidas, manejo de } \\
\text { nematoides, sombreamento na cultura da soja, vitrine de cultivares } \\
\text { de soja e algodão para safrinha e plantas de cobertura. }\end{array}$ \\
\hline \multirow{2}{*}{$\begin{array}{l}\text { APROSOJA- } \\
\text { MT }\end{array}$} & $\begin{array}{l}\text { II Simpósio } \\
\text { Agroestratégico: } \\
\text { Palestras }\end{array}$ & $\begin{array}{l}\text { Tema central: repensando agricultura do futuro } \\
\text { - Práticas agrícolas utilizando o Manejo Integrado de Pragas } \\
\text { (MIP) e o Manejo Integrado de Doenças (MID). } \\
\text { Palestra e discussões sobre o tema com base em pesquisas }\end{array}$ \\
\hline & $\begin{array}{l}\text { II Simpósio } \\
\text { Agroestratégico: Dia } \\
\text { de campo }\end{array}$ & $\begin{array}{l}\text { Tema central: repensando agricultura do futuro } \\
\text { - Práticas agrícolas utilizando o Manejo Integrado de Pragas } \\
\text { (MIP) e o Manejo Integrado de Doenças (MID). Atividade prática } \\
\text { no meio da lavoura de soja }\end{array}$ \\
\hline UNEMAT & $\begin{array}{l}\text { I Simpósio de } \\
\text { Tecnologias de } \\
\text { Produção Agrícola }\end{array}$ & $\begin{array}{l}\text { Tema central: Consequências do uso incorreto do Sistema } \\
\text { Plantio Direto } \\
\text { - Aspectos sobre Integração Lavoura-Pecuária-Floresta (ILPF) na } \\
\text { região centro-oeste do Brasil; } \\
\text { - Desafios fitossanitários do Sistema Plantio Direto; } \\
\text { - Formação de palhada em regiões tropicais; } \\
\text { - Uso correto de tecnologias de produção em cultivos comerciais. }\end{array}$ \\
\hline $\begin{array}{l}\text { Agrodinâmica } \\
\text { Pesquisa } \\
\text { Consultoria } \\
\text { Agropecuária }\end{array}$ & $7^{\circ}$ Jornada Técnica & $\begin{array}{l}\text { - Tecnologias geradas nas áreas experimentais próprias sobre } \\
\text { consorcio de plantas para cobertura do solo; } \\
\text { - Dados sobre o manejo de doenças da soja que atualmente } \\
\text { preocupam os produtores; } \\
\text { - Resultados de ensaio com } 5 \text { novas cultivares de soja } \\
\text { (transgênicas e não transgênicas). }\end{array}$ \\
\hline
\end{tabular}

Fonte: Elaborado pela autora (2016) 


\section{CONSIDERAÇÕES FINAIS}

O propósito deste estudo foi explorar as fontes de conhecimento/tecnologia para o agronegócio da soja no cenário mato-grossense. Nesse sentido os dados reunidos evidenciaram um quadro institucional nacional e local que contribui na pesquisa, desenvolvimento e transferência de tecnologias aplicadas ao cultivo do grão. Nesse quesito destaca-se a FMT que há 22 anos desenvolve trabalhos.

A condição atual do Estado de Mato como maior produtor brasileiro de soja, resulta da eficiência das instituições ligadas ao agronegócio da soja na produção e difusão de tecnologias para o sojicultor. Pertinente destacar no quesito acesso as fontes de conhecimento/tecnologia, a forte presença/ligação das revendas de insumos junto aos produtores, o que não é observado com a mesma intensidade em relação as demais instituições.

Nesse sentido, além de informações já destacadas, este estudo contribui para levantar uma discussão, a qual intriga e pode comprometer o status do Mato Grosso na produção do grão. Nos eventos e Dia de Campo realizados pela FMT, ficou evidente a preocupação com o fato de que há 16 safras a produtividade média da soja não aumenta no Estado (está entre 51 a $53 \mathrm{sc} / \mathrm{ha}$ ). Tal inquietação, baseada nas pesquisas que realiza, requer mudança nas atuais práticas do sojicultor, o qual precisa modificar a forma de manejar o solo, pois a monocultura (atualmente predominante) traz cada vez mais problemas para a planta, ao ponto de num futuro próximo comprometer o cultivo do grão. O que fazer? Para a FMT é preciso que o produtor deixe de investir somente em tecnologias embarcadas nos insumos. É necessário mudança de atitude quanto ao manejo do solo; essa tecnologia não está à venda. Considerando a forte presença das revendas e os interesses comerciais envolvidos, a FMT considera essa mudança de atitude um desafio bem maior do que fazer o Cerrado produzir na década de 1980. O produtor busca soluções prontas e imediatas, dai a dificuldade.

Diante dessa questão, aponta-se como sugestão para pesquisas futuras, estudos com os sojicultores para conhecer a capacidade para absorver e transformar o conhecimento que está disponível e disposição em se adaptarem para esse novo contexto, ou seja, mudar a forma de manejar o solo, não mais utilizando tecnologias de resultado imediato, mas sim, pensando na sustentabilidade do sistema no longo prazo. 


\section{REFERÊNCIAS}

LOURENZANI, Wagner Luiz. Modelo dinâmico para a gestão integrada da agricultura familiar. São Carlos, UFSCar, 2005. 192 p. Tese (Doutorado em Engenharia de Produção) Programa de Pós-graduação em Engenharia de Produção, Universidade Federal de São Carlos. São Carlos, 2005.

ANTONIAZZI, Laura et al. Tecnologias na agricultura brasileira e potenciais para cooperação com a África: contribuição para diálogos julho. Instituto de Estudos do Comércio e Negociações Internacionais - ICONE, 2013.

ASSOCIAÇÃO DOS PRODUTORES DE SOJA E MILHO DE MATO GROSSO (APROSOJA MT). A história da soja. Disponível em:< http://www.aprosoja.com.br/soja-emilho/a-historia-da-soja> Acesso em: 26 jan 2016.

ASSOCIAÇÃO DOS PRODUTORES DE SOJA E MILHO DE MATO GROSSO (APROSOJA-MT). Aprosoja realiza etapa prática de II Simpósio Agroestratégico. Disponível em: $<$ http://www.aprosoja.com.br/comunicacao/release/aprosoja-realiza-etapapratica-de-ii-simposio-agroestrategico>. Acesso em: 18 nov 2015.

BATALHA, M. O.; SILVA, A. L. Gerenciamento de sistemas agroindustriais: definições, especialidades e correntes metodológicas. In: BATALHA, C. M. O. (Org.). Gestão Agroindustrial. 3. ed. São Paulo: Atlas, 2012.

BATALHA, Mário Otávio. Gestão agroindustrial. 2. ed. São Paulo: Atlas, 2002.

BUAINAIM, Antônio Márcio; VIEIRA, Adriana Carvalho Pinto; VIEIRA JUNIOR, P. A. Análise da governança da cadeia da soja. Rio de Janeiro: Campus, 2006.

CAPETTI, Edson José. Agronegócio: por que o agronegócio e tão importante para a economia do Brasil? 2013. Hagah Rural. Disponível em:<

http://www.hagah.com.br/especial/rs/agricultura-e-pecuaria/19,1646,4112617,Por-que-oagronegocio-e-tao-importante-para-a-economia-do-Brasil.html> Acesso em: 11 out 2014.

CENTRO DE ESTUDOS AVANÇADOS EM ECONOMIA APLICADA (CEPEA).

Relatório PIBAgro-Brasil. Junho, 2014. Disponível em: $<$

http://www.cepea.esalq.usp.br/comunicacao/Cepea_PIB_BR_jun14.pdf $>$. Acesso em: 11 out 2014.

CENTRO UNIVERSITÁRIO DE VÁRZEA GRANDE (UNIVAG). A Univag. Disponível em:< http://www.univag.com.br/a-univag>. Acesso em: 05 dez. 2015.

COMPANHIA NACIONAL DE ABASTECIMENTO (CONAB). Acompanhamento da safra brasileira de grãos. V.2 - Safra 2014/15 N.10 - Décimo Levantamento Julho/2015.

Disponível em: 〈http://www.conab.gov.br〉. Acesso em: 28 ago 2015.

CONTINI, Elisio et al. Dinamismo da agricultura brasileira. Revista de Política Agrícola, Brasília, ano XIX, jul. 2010, p. 42-64.

CONTINI, Elisio. Potencial do agronegócio e gargalos são temas de seminário da AMCHAM. 2014. Disponível em:< http://sna.agr.br/potencial-do-agronegocio-e-gargalos-saotemas-de-seminario-da-amcham/>. Acesso em: 11 out 2014.

DAVIS, J. H.; GOLDBERG, R. A. A concept of agribusiness. Division of Research. Boston: Graduate School of Business Administration. Harvard University, 1957.

EMBRAPA AGROSSILVIPASTORIL. Disponível em:<

https://www.embrapa.br/agrossilvipastoril>. Acesso em 30 nov. 2016. 
EMBRAPA CERRADOS. A Embrapa cerrados. Disponível em: https://www.embrapa.br/cerrados/apresentacao. Acesso em: 01 fev. 2015.

EMPRESA MATO-GROSSENSE DE PESQUISA, ASSISTÊNCIA E EXTENSÃO RURAL (EMPAER-MT). Histórico. Disponível

em:〈http://www.empaer.mt.gov.br/empaer/index.asp?cod=6>. Acesso em 01 fev. 2015.

FUNDAÇÃO MT. Institucional: história. Disponível em:

<http://www.fundacaomt.com.br/institucional/historia.php>.Acesso em 02 fev. 2016

GAZZONI, Décio Luiz. A sustentabilidade da soja no contexto do agronegócio brasileiro e mundial. Londrina: Embrapa Soja, 2013.

HIRAKURI, Marcelo Hiroshi; LAZZAROTTO, Joelsio José. O agronegócio da soja nos contextos mundial e brasileiro. EMBRAPA soja, 2014.

I SIMPÓSIO DE TECNOLOGIAS DE PRODUÇÃO AGRÍCOLA. Disponível em:< http://aeatga.org/stpa/>. Acesso em 10 set. 2015.

Instituto Federal de Mato Grosso (IFMT). Institucional: sobre. Disponível em:< http://www.ifmt.edu.br/post/1000400/>. Acesso em 06 de fev. 2015.

IMEA. Entendendo o mercado da soja. 2015. Disponível em:

<http://www.imea.com.br/upload/pdf/arquivos/2015_06_13_Paper_jornalistas_boletins_Soja _Versao_Final_AO.pdf $>$. Acesso em: 28 ago 2015.

LAZZARINI, S. G.; NUNES, R. Competitividade do sistema agroindustrial da soja. São Paulo: PENSA/USP, 2000.

MINISTÉRIO DA AGRICULTURA, PECUÁRIA E ABASTECIMENTO (MAPA). Curso de propriedade intelectual \& inovação no agronegócio. Org. Luiz Otávio Pimentel. 2. ed. rev. e atual. - Brasília : MAPA ; Florianópolis :EaD/ UFSC, 2010.

MUTEIA, Helder. O papel do Brasil no combate a fome do mundo. In: Fundação MT.

Boletim de Pesquisa de Soja n. 15, 2011. Mato Grosso, Brasil. p.45 - 52.

OCDE-FAO. Perspectivas Agrícolas 2015-2024. Perspectivas Agrícolas no Brasil: desafios da agricultura brasileira 2015-2024.

ORGANIZAÇÕES ESTADUAIS DE PESQUISA AGROPECUÁRIA (OEPAS). Disponível em:<https://www.embrapa.br/oepas>. Acesso em: 01 fev. 2015.

PALUDO, Seneri Kernbeis; TIRIONI, Maria Amélia. Importância da soja para a atividade econômica de Mato Grosso e do Brasil. In: Fundação MT. Boletim de Pesquisa de Soja n. 15, 2011. Mato Grosso, Brasil. p. 53-64.

PARENTE, Pedro. Desafios e Oportunidades do Agronegócio Brasileiro no Mercado Mundial. 2011. Disponível em:< http://www.bmfbovespa.com.br/pt-br/download/Desafios-eoportunidades-do-agronegocio-brasileiro-no-mercado-mundial-Pedro-Parente.pdf $>$. Acesso em: 11 out 2014.

PORTER, M.E. Vantagem competitiva: criando e sustentando um desempenho superior. Rio de Janeiro: Campus, 1989.

POSSAS, M.; SALLES-FILHO, Sergio; SILVEIRA, José Maria da. An evolutionary approach to technological innovation in agriculture: some preliminary remarks. Cadernos de Ciência \& Tecnologia, v. 11, n. 1/3, p. 9-31, 1994.

RIBEIRO, Hugo de Carvalho. O grão de ouro nos trilhos do progresso. In: Fundação MT. Boletim de pesquisa de soja. N 16. 2013/2014. Mato Grosso, Brasil. p. 12-15. 
ROSCOE, Renato. Tecnologia e Inovação na agropecuária brasileira. Folha de Dourados. Dourados-MS, 09 março 2013. Disponível

em:<http://www.folhadedourados.com.br/noticias/brasil-mundo/tecnologia-e-inovacao-naagropecuaria-brasileira-por-renato-roscoe>. Acesso em: 09 ago. 2014

SANTOS, Joyce Aparecida Marques dos, et al;. O processo de inovação tecnológica na Embrapa e na Embrapa Agrobiologia: desafios e perspectivas. Perspectivas em Ciência da Informação, v. 17, n. 4, p. 175-194, 2012.

SENAR-MT. Quem somos. Disponível em:

<http://www.sistemafamato.org.br/portal/senar/quem_somos.php>. Acesso em: 01 dez. 2015.

SILVA, José Graziano da. O progresso técnico na agricultura. Cadernos de Ciência \& Tecnologia, v. 7, n. 1/3, p. 13-46, 1990.

SOARES NETO, Francisco José. Soja, a locomotiva do desenvolvimento. In: Fundação MT. Boletim de pesquisa de soja. N 16. 2013/2014. Mato Grosso, Brasil. p. 8-11.

SOUZA, Nali de Jesus. Desenvolvimento Econômico. 5. ed. São Paulo: Atlas, 2005.

UNIVERSIDADE DE CUIABÁ-MT (UNIC). Histórico. Disponível em: <http://www.unic.br/Paginas/Sobre-o-Grupo.aspx>. Acesso em: 01 dez. 2015.

UNIVERSIDADE DO ESTADO DE MATO GROSSO (UNEMAT). Histórico. Disponível em:< http://www.novoportal.unemat.br/?pg=universidade\&conteudo=1>. Acesso em: $01 \mathrm{dez}$. 2015 .

UNIVERSIDADE FEDERAL DO ESTADO DE MATO GROSSO (UFMT). Institucional. Disponível em:< http://www.ufmt.br/ufmt/site/secao/index/Cuiaba/1>. Acesso: em 30 nov. 2015.

VIEIRA FILHO, J. E. R.; DA SILVEIRA, J. M. F. Mudança tecnológica na agricultura: uma revisão crítica da literatura e o papel das economias de aprendizado. Revista de economia e Sociologia Rural, v. 50, n. 4, p. 717-738, out./dez. 2012.

VIEIRA FILHO, José Eustáquio Ribeiro. Inovação tecnológica e aprendizado agrícola: uma abordagem schumpeteriana. 2009. 154p. 2009. Tese de Doutorado. Tese (Doutorado em Teoria Econômica)-Unicamp, Campinas, 2009.

VIEIRA FILHO, José Eustáquio Ribeiro; CAMPOS, Antônio Carvalho; FERREIRA, Carlos Maurício. Abordagem alternativa do crescimento agrícola: um modelo de dinâmica evolucionária. Revista Brasileira de Inovação, v. 4, n. 2 jul/dez, p. 425-476, 2005.

VIEIRA FILHO, José Eustáquio Ribeiro; PINTO VIEIRA, Adriana Carvalho. A inovação na agricultura brasileira: Uma reflexão a partir da análise dos certificados de proteção de cultivares. Texto para Discussão, Instituto de Pesquisa Econômica Aplicada (IPEA), 2013.

ZYIBERSZTAJN, Décio; SCARE, Roberto Fava (Org.) Gestão da qualidade no agribusiness: estudos e casos. São Paulo: Atlas, 2003. 